\title{
PENGARUH MODEL PEMBELAJARAN GUIDED INQUIRY DAN MODIFIED FREE INQUIRY TERHADAP KEMAMPUAN BERPIKIR KRITIS SISWA PADA MATERI PENCEMARAN LINGKUNGAN DI SMA NEGERI 1 KOTAPINANG
}

\author{
Hasmi Syahputra Harahap ${ }^{1)}$, Nurlina Ariani Harahap ${ }^{2)}$ \\ ${ }^{1,2}$ Jurusan Pendidikan Biologi, Universitas Labuhan Batu \\ Email $^{1)}$ : hasmi.putraharahap@gmail.com \\ Email ${ }^{2}:$ nurlinaariani561@gmail.com
}

\begin{abstract}
ABSTRAK: Penelitian ini bertujuan untuk mengetahui pengaruh model pembelajaran inkuiri terhadap kemampuan berpikir kritis siswa materi pencemaran lingkungan di SMA Negeri 1 Kotapinang. Metode penelitian yang digunakan adalah quasi eksperimen dengan sampel sebanyak 3 kelas yang diambil dengan teknik cluster random sampling. Model pembelajaran inkuiri terbimbing diajarkan di kelas X-1, model pembelajaran berbasis inkuiri bebas termodifikasi diajarkan di kelas X-2, dan model pembelajaran berbasis tradisional diajarkan di kelas X-3. Instrumen yang digunakan dalam penelitian ini adalah tes keterampilan berpikir kritis berbentuk pilihan ganda. Teknik analisis data yang digunakan dalam penelitian ini adalah analisis kovariat dengan menggunakan program SPSS 23.0 for Windows. Hasil penelitian menunjukkan bahwa terdapat pengaruh model pembelajaran inkuiri terhadap kemampuan berpikir kritis siswa ( $\mathrm{F}=26.015$; $\mathrm{P}=0.000$ ). Keterampilan berpikir kritis siswa yang dibelajarkan dengan model pembelajaran inkuiri terbimbing $(75,00 \pm 8,701)$ tidak berbeda nyata dengan model pembelajaran inkuiri bebas termodifikasi $(79,03 \pm 8,930)(\mathrm{P}=0,161)$, dan tidak berbeda signifikan dengan model pembelajaran tradisional $(70,00 \pm 10,142)$ $(\mathrm{P}=0,062)$. Namun berbeda sangat signifikan antara model pembelajaran inkuiri bebas modifikasi dengan tradisional $(\mathrm{P}=0,000)$. Hasil penelitian ini diharapkan guru dapat menerapkan model pembelajaran inkuiri terbimbing atau model pembelajaran inkuiri bebas termodifikasi saat mengajar materi pencemaran lingkungan guna meningkatkan daya pikir kritis siswa.
\end{abstract}

Kata Kunci : Pertanyaan Terpandu, Pertanyaan Bebas Modifikasi, Keterampilan Berpikir Kritis, Polusi Lingkungan.

ABSTRACT: This study aims to determine the effect of inquiry based learning model on students'critical thinking skill of the environmental pollution topic at SMA Negeri 1 Kotapinang. The research method used is quasi experiment with sample as much as 3 classes, those are taken by using the technic of cluster random sampling. Guided inquiry based learning model is taught in class X-1, modified free inquiry based learning model is taught in class $X-2$, and traditional based learning model is taught in class X-3. The instruments are used in this study are critical thinking skill test which form multiple choice. The technique of data analysis used in this study is analysis covariat by using the program of SPSS 23.0 for Windows. The study results showed that there is effect of inquiry based learning model on students'critical thinking skill ( $F=26.015$; $P=0.000)$. Students' critical thinking skill that were taught by guided inquiry based learning model (75.00 \pm 8.701$)$ not different significant with modified free inquiry based learning model $(79.03 \pm 8.930)(P=0,161)$, and not different significant with traditional based learning model $(70.00 \pm 10.142)(P=0,062)$. But different very significant between modified free inquirybased learning model with traditional $(P=0,000)$.

Bio-Lectura: Jurnal Pendidikan Biologi, Vol 8, No 2,Oktober 2021 
The result of this study is expected from the teachers to apply guided inquiry or modified free inquiry based learning model when they are teaching environmental pollution topic in order to increase students' 'ritical thinking.

Keywords: Guided Inquiry, Modified Free Inquiry, Critical Thinking Skill, Environmental Pollution.

\section{PENDAHULUAN}

PISA (Programme for International Student Assessment) adalah sebuah program yang diinisiasi oleh negara-negara yang tergabung dalam OECD (Organisation for Economic Co-operation and Development). PISA pertama kali diselenggarakan pada tahun 2000 untuk membantu negara-negara dalam mempersiapkan sumber daya manusia agar memiliki kompetensi yang sesuai dengan yang diharapkan dalam pasar internasional. Hasil survei PISA 2018 bahwa kemampuan siswa Indonesia dalam kategori sains memperoleh skor 396, jauh dibawah rata-rata skor OECD sebesar 489. PISA menekankan kepada keterampilan abad 21 yang memungkinkan dimasukkan dalam sistem pendidikan. Terbitan OECD "The Future of Education and Skill: An OECD 2030" (Pratiwi, 2019).

Berpikir kritis merupakan berpikir secara beralasan dan reflektif dengan menekankan pada pembuatan keputusan tentang apa yang harus dipercayai atau dilakukan (Ennis, 1993). Siswa yang berpikir kritis mampu mempertahankan pendapatnya, membuat perbandingan, menarik kesimpulan, mengevaluasi argumen dan memecahkan masalah. Saat ini kecakapan berpikir kritis siswa belum ditangani secara sungguh-sungguh oleh para guru di sekolah sehingga siswa masih banyak yang kurang terampil menggunakan kemampuan berpikir kritis yang berdampak pada hasil belajar siswa rendah. Pada umumnya pembelajaran diarahkan untuk menghafal dan menimbun informasi, sehingga siswa pintar secara teoritis tetapi miskin aplikasi. Akibatnya kemampuan berpikir kritis menjadi susah untuk dikembangkan (Ariyati, 2010).

Pembelajaran biologi merupakan suatu proses penemuan dan menekankan pada pemberian pengalaman belajar secara langsung. Materi biologi SMA khususnya di kelas $\mathrm{X}$ tentang pencemaran lingkungan merupakan salah satu materi yang berhubungan secara langsung dengan kehidupan seharisehari. Namun, pada praktiknya selama ini proses pembelajaran tentang pencemaran lingkungan yang dilakukan oleh guru di dalam kelas masih menggunakan variasi pembelajaran yang rendah yang umumnya masih berorientasi pada guru (teacher centered). Strategi pembelajaran yang dilakukan oleh guru selama ini adalah strategi pembelajaran konvensional yang umumnya masih menggunakan metode ceramah dan belum memanfaatkan lingkungan sebagai sumber belajar, sehingga masih belum 
mampu mengaktifkan peserta didik secara optimal dalam kegiatan belajar dan belum mampu membiasakan peserta didik untuk berpikir kritis.

Permasalahan yang ditemukan di SMA Negeri 1 Kotapinang dari hasil observasi awal dan komunikasi langsung dengan guru bidang studi biologi diketahui bahwa peserta didik masih memiliki kemampuan berpikir kritis rendah yang ditunjukkan dengan minimnya aktivitas bertanya, menjawab, menanggapi dan mengemukakan pendapat, menalar, belum terbiasa menyelesaikan suatu masalah dengan baik, dan mencoba mengambil suatu kesimpulan masih sangat kurang dalam kegiatan pembelajaran di kelas. Guru juga masih menggunakan strategi pembelajaran tradisional yang didominasi ceramah sehingga proses pembelajaran berlangsung satu arah, siswa mendengarkan dan mencatat, sekali-kali bertanya dan menjawab pertanyaan guru. Hal ini berdampak pada pencapaian prestasi belajar biologi peserta didik.

\section{Model}

pembelajaran merupakan usaha untuk memperoleh kesuksesan dan keberhasilan dalam mencapai tujuan pembelajaran. Model pembelajaran dirancang dengan materi dan prosedur pembelajaran untuk mencapai tujuan pembelajaran. Salah satu model pembelajaran yang dapat membantu peserta didik untuk mencapai tujuan pembelajaran adalah model pembelajaran inquiry yang merupakan model pembelajaran yang berpusat pada peserta didik, yang mampu mengaktifkan peserta didik secara maksimal untuk mencari dan menemukan sendiri inti materi pelajaran, membangkitkan diskusi, juga dapat meningkatkan kemampuan berpikir kritis. Model pembelajaran inquiry yang dibelajarkan adalah model pembelajaran inkuiri terbimbing dan inkuiri bebas termodifikasi.

\section{METODE PENELITIAN}

Populasi dalam penelitian ini adalah seluruh siswa kelas X SMA Negeri 1 Kotapinang. Sampel yang digunakan dalam penelitian ini diambil sebanyak 3 kelas yang ditentukan secara acak dengan menggunakan teknik cluster random sampling. Pengacakan dilakukan dengan cara undian, sehingga diperoleh kelas X-1 sebagai kelas eksperimen pertama yang dibelajarkan dengan menggunakan model pembelajaran inkuiri terbimbing (guided inquiry) dan X-2 sebagai kelas eksperimen kedua yang dibelajarkan dengan model pembelajaran inkuiri bebas termodifikasi (modified free inquiry) dan X-3 sebagai kelas kontrol yang dibelajarkan dengan pembelajaran tradisional.

Variabel bebas adalah model pembelajaran inkuiri terbimbing, inkuiri bebas termodifikasi dan pembelajaran tradisional. Variabel terikat yaitu kemampuan berpikir kritis. Penelitian ini menggunakan metode eksperimen semu (quasi experimental research), yang terdiri dari dua kelompok eksperimen (guided inquiry dan modified free inquiry) dan satu kelompok kontrol (tradisional), dirancang dengan menggunakan pretest-posttest 
experiment and control group disusun dan dikembangkan sendiri design.

oleh peneliti dengan mengacu pada

Tabel 1. Pretest-Posttest Experiment and Control Group Design bentuk form Cornell Critical Thinking Test Series (The Cornell ClassReasoning Test, Form $X$ ) yang

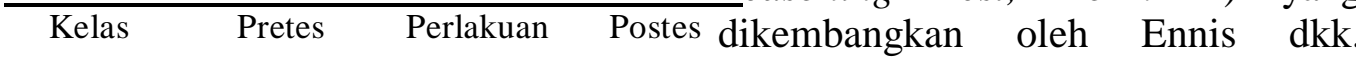

\begin{tabular}{llllll}
\hline $\mathrm{X}-1$ & $\mathrm{H}$ & $\mathrm{Y}$ & $\mathrm{H}$ & (1964), tetapi telah dimodifikasi
\end{tabular}

$\begin{array}{lllll}\mathrm{X}-2 & \mathrm{H} & \mathrm{Y} & \mathrm{H} & \text { berdasarkan materi pencemaran }\end{array}$

$\begin{array}{lllll}\mathrm{X}-3 & \mathrm{H} & \mathrm{Y} & \mathrm{H} & \text { lingkungan yang disusun sesuai }\end{array}$
dengan aspek berpikir deduktif dan induktif. Tes ini berisi informasiinformasi kognitif, afektif atau konasi dalam bentuk berpikir secara deduksi

Keterangan:

Y1: Perlakuan dengan menggunakan model pembelajaran guided inquiry

Y2: Perlakuan dengan menggunakan model pembelajaran modified free

inquiry

Y3: Perlakuan dengan menggunakan pembelajaran tradisional

H: Kemampuan berpikir kritis siswa



Gambar 1. Diagram Alir Penelitian

Tes kemampuan berpikir kritis maupun induksi dengan bentuk tes pilihan ganda beralasan dengan tiga pilihan jawaban (ya, tidak, dan mungkin). Setiap jawaban benar diberi skor 1, sedangkan jawaban salah diberi skor 0, dan akan dikonversikan kepada nilai dengan rentang $0-100$ sehingga akan diperoleh nilai dari tes kemampuan berpikir kritis. Uji coba instrument penelitian dilakukan dengan mengetahui validitas, reliabilitas, tingkat kesukaran, dan daya pembeda.

Teknik analisis deskriptif dimaksudkan untuk mendiskripsikan data hasil penelitian meliputi mean, median, modus, varians, standar deviasi, nilai minimum dan nilai maksimum data. Uji normalitas data dimaksudkan untuk menentukan normal tidaknya distribusi data penelitian, artinya apakah penyebarannya dalam populasi bersifat normal. Uji normalitas dilakukan dengan uji KolmogorovSmirnov. Uji homogenitas data dimaksudkan untuk mengetahui perbedaan varians data, artinya apakah kelompok-kelompok yang membentuk sampel berasal dari populasi yang sama (penyebarannya dalam populasi bersifat homogen). Uji homogenitas data dilakukan dengan uji Levene's Test. Setelah persyaratan

Bio-Lectura: Jurnal Pendidikan Biologi, Vol 8, No 2,Oktober 2021 
terpenuhi selanjutnya dilakukan pengujian hipotesis penelitian pada kemampuan berpikir kritis yang dianalisis dengan menggunakan teknik analisis kovariat (anacova). Jika hasil analisis menggambarkan adanya pengaruh yang signifikan antara ketiga kelas perlakuan yang berbeda tersebut, maka dilakukan uji lanjut dengan uji Tukey's. Keseluruhan data penelitian dianalisis dengan menggunakan aplikasi SPSS 23.0 for windows.

\section{HASIL DAN PEMBAHASAN \\ 3.1. Deskripsi Pretes dan Postes Kemampuan Berpikir Kritis}

Rata-rata nilai dan standar deviasi pretes siswa pada kelas model pembelajaran guided inquiry adalah $47,78 \pm 13,546$ dan rata-rata nilai dan standar deviasi pretes siswa pada kelas model pembelajaran modified free inquiry adalah 51,25 \pm 14,411 serta rata-rata nilai dan standar deviasi pretes siswa pada kelas model pembelajaran tradisional adalah 59,86 \pm 14,711.

Rata-rata nilai dan standar deviasi postes siswa pada kelas model pemebelajaran guided inquiry adalah $75,00 \pm 8,701$ dan rata-rata nilai dan standar deviasi postes siswa pada kelas model pembelajaran modified free inquiry adalah 79,03 $\pm 8,930$ serta ratarata nilai dan standar deviasi postes siswa pada kelas model pembelajaran tradisional adalah 70,00 $\pm 10,142$.

\subsection{Data Uji Normalitas Data Pretes dan Postes Kemampuan Berpikir Kritis Siswa}

Data pretes dan postes kemampuan berpikir kritis dengan model pembelajaran guided inquiry, modified free inquiry, dan tradisional.

Tabel 2. Data Uji Normalitas Data

Pretes dan Postes Kemampuan Berpikir Kritis Siswa

\begin{tabular}{|c|c|c|c|c|}
\hline \multirow{3}{*}{$\begin{array}{c}\text { Model } \\
\text { Pembelajaran }\end{array}$} & \multicolumn{4}{|c|}{ Kolmogorov-Smirnov } \\
\hline & \multicolumn{2}{|c|}{ Pretes } & \multicolumn{2}{|c|}{ Postes } \\
\hline & Sig. & Ket. & Sig. & Ket. \\
\hline Guided & 0,002 & Tidak & 0,013 & Tidak \\
\hline Inquiry & & Normal & & Normal \\
\hline Modified & 0,046 & Tidak & 0,030 & Tidak \\
\hline Free Inquiry & & Normal & & Normal \\
\hline Tradisional & 0,059 & Normal & 0,059 & Normal \\
\hline
\end{tabular}

Berdasarkan tabel di atas, bahwa hasil pengujian normalitas data terhadap pretes dan postes kemampuan berpikir kritis siswa dari setiap kelas model pembelajaran guided inquiry, modified free inquiry, dan tradisional menunjukkan bahwa sebaran data berdistribusi normal $(\mathrm{P}>0,05)$ yaitu hanya pada kelas model pembelajaran tradisional.

\subsection{Uji Homogenitas Data}

Hasil uji homogenitas data pretes kemampuan berpikir kritis siswa dinyatakan homogen $(\mathrm{P}=0,716>0,05)$ dan data postes kemampuan berpikir kritis siswa juga dinyatakan homogen $(\mathrm{P}=0,705>0,05)$.

\subsection{Analisis Data}

Pengujian hipotesis dilakukan dengan menggunakan teknik Analysis Covariat (Anacova) untuk data kemampuan berpikir kritis siswa berdasarkan data pretes dan postes.

\subsection{Pengaruh Model Pembelajaran Terhadap Kemampuan Berpikir Kritis}

Hasil Anacova dengan
menggunakan


bahwa model pembelajaran sangat signifikan berpengaruh terhadap kemampuan berpikir kritis siswa $(\mathrm{F}=26.015 ; \mathrm{P}=0,000)$ dan data pretes berkorelasi dengan data postes pada kemampuan berpikir kritis siswa $(\mathrm{F}=62.465 ; \mathrm{P}=0,000)$. Selanjutnya hasil uji Tukey menunjukkan bahwa kemampuan berpikir kritis siswa yang dibelajarkan dengan model pembelajaran guided inquiry 75,00 \pm $8,701(\bar{X} \pm S B)$ tidak berbeda signifikan dengan kemampuan berpikir kritis siswa yang dibelajarkan dengan model pembelajaran modified free inquiry $79,03 \pm 8,930(\bar{X} \pm S B)(\mathrm{P}=0,161)$ dan tidak berbeda signifikan dengan yang dibelajarkan menggunakan pembelajaran tradisional $70,00 \pm$ $10,142 \quad(\bar{X} \pm S B) \quad(\mathrm{P}=0,062)$. Namun, berbeda sangat signifikan antara model modified free inquiry dan tradisional $(\mathrm{P}=0,00)$. pembelajaran guided inquiry memberikan pengaruh yang lebih rendah dibandingkan model pembelajaran modified free inquiry dan lebih tinggi dibandingkan pembelajaran tradisional.

\subsection{Pengaruh Model Pembelajaran Guided Inquiry, Modified Free Inquiry dan Pembelajaran Tradisional Terhadap Kemampuan Berpikir Kritis Siswa}

Berdasarkan hasil pengujian analisis kovariat diperoleh $(\mathrm{P}=0,000<0,05)$. Dengan demikian, terima $\mathrm{H}_{\mathrm{a}}$ atau tolak $\mathrm{H}_{0}$ sehingga disimpulkan ada pengaruh yang sangat signifikan antara penggunaan model pembelajaran guided inquiry, modified free inquiry, dan pembelajaran tradisional terhadap kemampuan berpikir kritis siswa pada materi pencemaran lingkungan di SMA Negeri 1 Kotapinang. Hal ini sesuai dengan penelitian Susanti (2013) yang menyatakan bahwa pembelajaran dengan menggunakan inkuiri terbimbing terbukti meningkatkan kemampuan berpikir kritis siswa yang meliputi aspek inkuiri diantaranya merumuskan masalah, merumuskan Keterangan:

a-a : Tidak berbeda signifikan $a-b$ : Berbeda signifikan

Gambar 1. Pengaruh Model

Pembelajaran Terhadap

Kemampuan Berpikir Kritis

Siswa Kelas X SMA Negeri

1 Kotapinang $(\mathrm{P}=0,000<$ $0,05)$

Berdasarkan rata-rata nilai kemampuan berpikir kritis siswa menunjukkan bahwa model hipotesis, mengumpulkan data dan membuat kesimpulan. Begitu juga dengan hasil penelitian yang dilakukan oleh Wilson, Taylor, Kowalski, dan Carlson di BCSS Center for Research and Evaluation di Colorado (2010) menyatakan bahwa inquiry based learning dapat meningkatkan pengetahuan siswa dan juga dapat meningkatkan kemampuannya dalam berargumentasi dan memberikan alasan 
yang logis. Quitadamo, Faiola, Johnson, dan Kurtz (2011) melaporkan bahwa pembelajaran dengan menggunakan CBI (Community Based Inquiry) menunjukkan peningkatan kemampuan berpikir kritis siswa secara signifikan dibandingkan siswa kelompok tradisional dan kelompok gabungan tradisional-CBI. Berdasarkan penelitian Hapsari, Suciati, dan Marjono (2012) yang dilaksanakan di SMA Negeri Gondangrejo pada semester II tahun pelajaran 2011/2012, bahwa terdapat pengaruh yang signifikan pada penggunaan model inkuiri terbimbing dengan diagram $\mathrm{V}$ (Vee) dalam pembelajaran biologi terhadap kemampuan berpikir kritis dan hasil belajar siswa.

Menurut Sanjaya (dalam Suprihatiningrum, 2013) model inkuiri adalah rangkaian kegiatan pembelajaran yang menekankan pada proses berpikir secara kritis dananalitis untuk mencari sendiri jawaban dari suatu masalah yang dipertanyakan. Inkuiri diawali dengan kegiatan pengamatan dalam upaya untuk memahami suatu konsep dengan siklus terdiri dari kegiatan mengamati, bertanya, menyelidiki, menganalisis, dan merumuskan teori, baik secara individu maupun berkelompok. Kemudian mengembangkan dan sekaligus menggunakan keterampilan berpikir kritis.

Berdasarkan hasil penelitian oleh Saputri (2014) menunjukan bahwa penerapan model inkuiri terbimbing dapat meningkatkan kemampuan berpikir kritis siswa setelah dilaksanakan pembelajaran dengan menggunakan inkuiri terbimbing. Model inkuiri merupakan model denganrangkaian kegiatan pembelajaran yang menekankan pada proses berpikir secara kritis dan analitis untuk mencari dan menemukan sendiri jawaban dari suatu masalah yang dipertanyakan. Proses berpikir itu sendiri biasanya dilakukan melalui tanya jawab antara guru dan siswa.

Berpikir kritis merupakan suatu proses yang terarah dan jelas yang digunakan dalam kegiatan mental seperti memecahkan masalah, mengambil keputusan, membujuk, menganalisis asumsi dan melakukan penelitian ilmiah. Berpikir kritis adalah kemampuan untuk berpendapat dengan cara yang terorganisasi. Berpikir kritis merupakan kemampuan untuk mengevaluasi secara sistematis bobot pendapat pribadi dan pendapat orang lain. Berpikir kritis secara esensial adalah proses aktif dimana seseorang memikirkan berbagai hal secara mendalam, mengajukan pertanyaan untuk diri sendiri, menemukan informasi yang relevan untuk diri sendiri daripada menerima berbagai hal dari orang lain (Dewey dalam Fisher, 2009).

Inkuiri bebas termodifikasi (modified free inquiry) adalah jenis inkuiri dimana sebagian besarperencanaan dibuat oleh guru. Selain itu guru menyediakan kesempatan petunjuk yang cukup luas kepada siswa. Pada pembelajaran inkuiri guru memberikan petunjukpetunjuk kepada siswa seperlunya. 
Petunjuk tersebut dapat berupa pertanyaan-pertanyaan yang membimbing dan memberi kebebasan kepada siswa agar mampu mencari sendiri arah dan tindakan-tindakan yang harus dilakukan untuk memecahkan masalah yang diberikan guru. Siswa bekerja merumuskan prosedur, menganalisis hasil dan mengambil kesimpulan secara mandiri, sedangkan dalam hal menentukan topik, pertanyaan dan bahan penunjang, guru berperan sebagai fasilitator (Rahmatsyah dan Simamora, 2011). Tindakan tersebut dilakukan agar siswa dapat berpikir secara kritis dan mencari sendiri konsep materi khususnya pada pencemaran lingkungan.

Kondisi ini membuktikan bahwa pelaksanaan pembelajaran dengan menggunakan model inkuiri dapat meningkatkan kemampuan berpikir kritis siswa. Penggunaan model inkuiri dalam pembelajaran menempatkan siswa untuk memahami secara mendalam materiyang diajarkan melalui proses pencarian yang siswa lakukan. Konsep yang didapatkan siswa akan lebih kuat dan tidak hanya bersifat hafalan. Hal tersebut difasilitasi dengan pemberian soal yang tidak hanya dalam taraf hafalan saja sehingga kemampuan berpikir kritis siswa meningkat yang dibuktikan dengan peningkatan pada setiap indikator kemampuan berpikir kritis. Tujuan berpikir kritis adalah untuk mencapai pemahaman yang mendalam. Hal ini sesuai dengan pernyataan oleh Suhari (2010) yang menyimpulkan bahwa penerapan model pembelajaran inkuiri bebas termodifikasi untuk siswa SMA pada pelajaran biologi dimana siswa yang dibelajarkan dengan menggunakan pembelajaran inkuiri, mengalami peningkatan terhadap hasil belajar, sikap, kemampuan pemecahan masalah dan keterampilan proses dalam penilaian dibandingkan dengan siswa yang dibelajarkan dengan menggunakan pembelajaran tradisional.

\section{KESIMPULAN}

Berdasarkan hasil penelitian dan pembahasan yang telah diuraikan sebelumnya, maka kesimpulan dalam penelitian ini adalah terdapat pengaruh pembelajaran yang sangat signifikan dari penggunaan model pembelajaran guided inquiry, modified free inquiry, dan tradisional terhadap kemampuan berpikir kritis siswa pada materi pencemaran lingkungan di SMA Negeri 1 Kotapinang. Kemampuan berpikir kritis siswa yang dibelajarkan dengan model guided inquiry tidak berbeda secara signifikan dengan model modified free inquiry dan tidak berbeda secara signifikan dengan pembelajaran tradisional. Namun, berbeda sangat signifikan antara model modified free inquiry dan tradisional .

Terima kasih banyak kepada Pemerintah terkhusus Kementerian Pendidikan, Kebudayaan, Riset, dan Teknologi (Kemendikbudristek) atas dukungannya dalam program penelitian di Indonesia.

\section{DAFTAR PUSTAKA}

Ariyati, E. (2010). Pembelajaran Berbasis Praktikum untuk Meningkatkan Kemampuan 
Berpikir Kritis Mahasiswa. Jurnal Matematika dan IPA , 1 (2), 1-11.

Ennis, R. (1993). Critical Thinking Assessment. Theory into Practice , 32 (3), 179-186.

Fisher, A. (2009). Berpikir Kritis: Sebuah Pengantar. Jakarta: Erlangga.

Hapsari, D. P., Suciati, S., dan Marjono. (2012). Pengaruh Model Inkuiri Terbimbing dengan Diagram V (Vee) dalam Pembelajaran Biologi terhadap Kemampuan Berpikir Kritis dan Hasil Belajar Siswa. Pendidikan Biologi, 4(3): 16-28.

Maryam, K. I. (2019). Pengaruh Model Pembelajaran Inkuiri terhadap Keterampilan Berpikir Kritis Siswa Kelas XI MIA MAN 2 Mataram. Jurnal Pijar MIPA , 14 (3), 154-161.

Masitoh, I. D. (2017). Pengaruh Model Pembelajaran Inkuiri Terbimbing terhadap Kemampuan Berpikir Kritis Siswa Kelas X MIA pada Materi Pencemaran Lingkungan di Surakarta. Jurnal Bioedukasi , 10 (1), 71-79.

Pratiwi, I. (2019). Efek Program PISA terhadap Kurikulum di Indonesia. Jurnal Pendidikan dan Kebudayaan , 4 (1), 51-71.

Quitadamo, I. J., C. L. Faiola, J. E. Johnson, and M. J. Kurtz. (2011). Community-based Inquiry Improves Critical Thinking in General Education Biology. CBE-Life Sciences Education, 7(3): 327-337.
Rahmatsyah dan Simamora, H. (2011). Pengaruh Keterampilan Proses Sains melalui Model Pembelajaran Inkuiri Terbimbing terhadap Hasil Belajar Siswa pada Materi Pokok Gerak di Kelas VII SMP. Jurnal Penelitian Inovasi Pendidikan Fisika, 3(2): 15-16.

Sanjaya, W. (2011). Strategi Pembelajaran Berorientasi Standar Proses Pendidikan. Jakarta: Kencana Prenada Media Group.

Saputri, N. I. (2014). Upaya Meningkatkan Kemampuan Berpikir Kritis Siswa Kelas V melalui Inkuiri Terbimbing pada Mata Pelajaran IPA di SDN Punukan, Wates, Kulon Progo Tahun Ajaran 2013/2014. Skripsi. Yogyakarta: Sekolah Sarjana Universitas Negeri Yogyakarta.

Suhari. (2010). Metode Pembelajaran Inkuiri Terbimbing Bebas Termodifikasi dan Keterampilan Proses Terhadap Hasil Belajar Siswa Mata Pelajaran IT. Tesis. Pascasarjana. Surakarta: Universitas Sebelas Maret.

Suprihatiningrum, J. (2013). Strategi Pembelajaran Teori dan Aplikasi.Yogyakarta: Ar-Ruzz Media.

Susanti, Dini. (2013). Pengembangan Keterampilan Berpikir Kritis dan Penguasaan Konsep Siswa SMA Melalui Pembelajaran Inkuiri Terbimbing Pada Materi Alkana. Bandung: Universitas Pendidikan Indonesia. 
Wilson, D. C., Taylor, J. A., Kowalski, S. M., Carlson, J. (2010). The Relative Effects and Equity Inquiry-Based and Commonplace Science Teaching on Students' Knowledge, Reasoning, and Argumentation. Journal of Research in Science Teaching, 47(3): 276-301. 